\title{
Assosciation between Emotional intelligence and response to periodontal therapy.
}

\author{
Dr Surekha Rathod, Dr Priya Mehta, Dr Farooque Khan
}

\begin{abstract}
It is now acknowledged that psychosocial and psychological factors may influence the etiology of periodontal disease.It has been proposed that patients with a more positive view of themselves were more likely to comply with continued maintenance therapy. The aim of this pilot study is to find the relationship between different domains of emotional intelligence and the response to a standardized initial treatment for chronic periodontitis.in our present study, the socio-economic and behavioural factors such as tobacco smoking were found to be related to treatment outcome measures in terms of plaque index, bleeding index, probing depth and clinical attachment loss. The size of the sample was small and did not allow for multivariate modelling. There is need for further research in order to test the effect of EI domains on the uptake of a positive behaviour such as smoking cessation following the introduction of smoking counselling in periodontal therapy.
\end{abstract}

\section{Introduction}

It is well known that successful long term periodontal therapy requires exceptional patient compliance to a periodontal maintenance program. Although maintenance is necessary to retain benefits of the treatment and to prevent relapse the achievement of the behavioural change required to establish adequate patient control remains a constant challenge to the periodontist. $(1,2,3)$

It is now acknowledged that psychosocial and psychological factors may influence the etiology of periodontal disease. Eg patients with higher levels of work stress and patient with more negative life events are significantly more likely to have periodontal disease. In contrast, protective factors are associated with maintenance of health. Eg. patients with better quality and better coping mechanisms or higher levels of social support are less likely to have periodontal disease. Hence social behavioural, cultural and economic factors have also been implicated in determining patterns of compliance, the influence of personality characteristics on attitude and driving these behavioural responses remains to be carefully explored (4)

Very few studies have seen the association between these factors and the outcome of periodontal treatment. It has been proved that the response to periodontal treatment is better in patients with a more rigid personality and a less stressful psychosocial situation in the past than in patients with more psychosocial strain and passive dependent traits. Also it has been proposed that patients with a more positive view of themselves were more likely to comply with continued maintenance therapy. Further it has been proposed that the subject's responses to stress may be a key determinant of the overall effect of stress.(5)

Emotional quotient is defined as the ability to perceive, control, and evaluate emotions. EI is a subset of social, practical, and personal intelligence, which assists thought by generating and regulating emotions to promote emotional and intellectual growth. One of the test to measure EI is the Mayer-Salovey-Caruso Emotional Intelligence Test. It has been shown that a variety of important outcomes have been predicted from EI. For example, as EI rises, so does academic performance, measures of relatedness, and ability to communicate motivating messages. An individual with high EI has better ability to perceive, manage, and understand emotions; less likely to engage in problematic behaviors, have higher verbal and other types of intelligence, and have more prosocial interactions.(6)

Studies in past have tested association of EI with mental health, smoking and health-related quality of life. From these studies it can be said that different domains within the EI concept can have individual effects on health, behaviour and subjective quality of life.(7)

Therefore, the aim of this pilot study is to find the relationship between different domains of emotional intelligence and the response to a standardized initial treatment for chronic periodontitis.

\section{Material and Methods}

This clinical pilot study was conducted at the Department of Periodontics and Implatology, VSPM Dental College and Research Centre, Nagpur after the approval from institutions ethics committee. Twenty five patients with chronic periodontitis participated in the study. The inclusion criteria for patients were: age range between 20 and 60 years; minimum of 10 teeth in each arch; minimum of one tooth with plaque; minimum of one tooth with bleeding; minimum of two teeth with pocket depths $4 \mathrm{~mm}$. The exclusion criteria included those; at risk of infective endocardititis; with systemic diseases that ca adversely affect host defence systems; using 
long-term chlorhexidine mouthwash; taking medication that might contribute to gingival overgrowth. An informed consent was signed from the patients.

At the first appointment, participants were interviewed in a separate interview room. In the interview, the participants were asked to fill the structured questionnaire to assess their demographic characteristics, periodontal health-related behavioural factors, and their EI. Before starting the study piloting of the questionnaire was conducted in five subjects to test the understanding of the questions, to identify possible queries and to estimate the time taken to fully complete it. The socio-demographic and behavioural factors included age, gender, marital status, level of education, employment status, reported tobacco consumption, oral hygiene habits and dental attendance. Assessment of EI was carried out using a questionnaire as described by Dr.SK Mangal (8)

EI is divided into three different areas: emotion awareness, competencies and values and beliefs, and each area is divided into different domains. The area of "emotional awareness" includes assessment awareness emotional awareness of others as domains, interpersonal management \& intra-personal management. The clinical examination was carried out in the Department of periodontics. Buccal and lingual surfaces were assessed for presence of plaque and bleeding after probing \& clinical attachment level.After the interview and clinical examination, participants received a standardized initial periodontal treatment. The treatment included two visits, 1 week apart. In the first visit, the patients received $10 \mathrm{~min}$. of oral hygiene instruction which included tooth brushing (Bass 1954), flossing and tongue brushing instruction. Patients also received supragingival scaling and polishing in two quadrants of one side of the mouth. In the second visit, oral hygiene instruction was re-inforced for $5 \mathrm{~min}$. and scaling and polishing in the remaining two quadrants was carried out. The selection of each side of the mouth to be treated first was systematically alternated according to patients' entry in the research. Participants were kept on follow-up recall for 3 weeks after completion of standardized periodontal treatment .During follow-up, plaque and bleeding levels were evaluated using the same criteria used in the baseline examination. The changes between baseline and follow-up in the plaque index score were used to assess behaviour change which indicated compliance of the patient with the oral hygiene instruction given during the treatment. The biological responses in the patients' periodontal tissue were assessed by the changes between baseline and follow-up in the bleeding score.

\section{Results}

Table-1 Frequency distribution of independent variables in study sample

\begin{tabular}{|l|l|l|}
\hline Table-1 & N & $\%$ \\
\hline Level Of Education & 11 & \\
\hline Low & 14 & 44 \\
\hline High & & 56 \\
\hline Employment Status & & \\
\hline Employed & 14 & 56 \\
\hline Un Employed & 11 & 44 \\
\hline & & \\
\hline & & \\
\hline Hours Of Work & & \\
\hline Full & 13 & 52 \\
\hline Part Time & 12 & 48 \\
\hline & & \\
\hline Maraital Status & & \\
\hline Married & 16 & 64 \\
\hline Un Married & 09 & 36 \\
\hline & & \\
\hline & & \\
\hline Smoking & & \\
\hline Smokers & 11 & 56 \\
\hline Non Smokers & 14 & \\
\hline & & 54 \\
\hline Gender & & \\
\hline Male & 14 & \\
\hline Female & 11 & \\
\hline
\end{tabular}


Table-2 Individual patient data on Bleeding index at baseline and follow-up

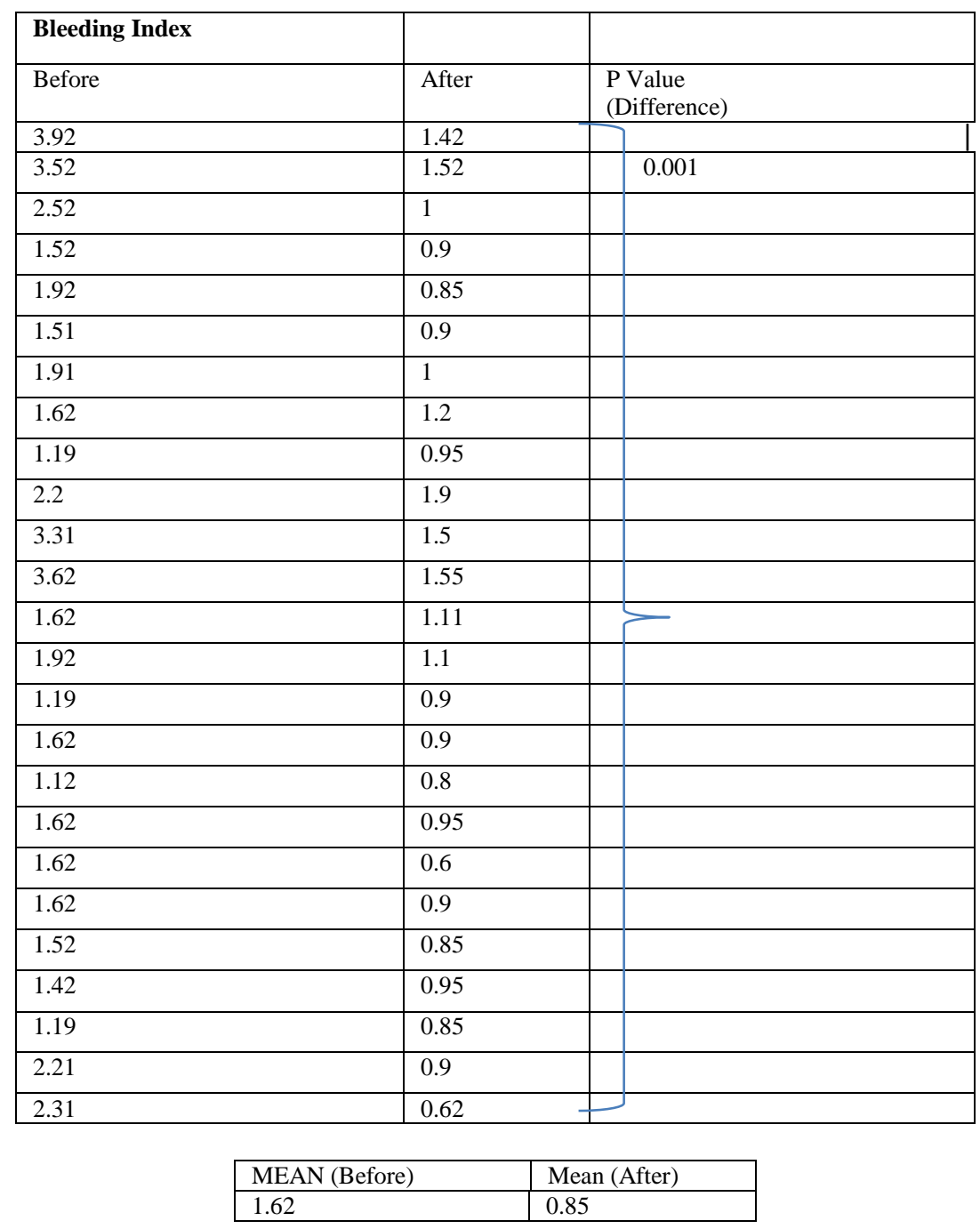


Assosciation between Emotional intelligence and response to periodontal therapy.

Table-3 Individual patient data on Plaque index at baseline and follow-up

\begin{tabular}{|c|c|c|}
\hline $\begin{array}{l}\text { PLAQUE } \\
\text { INDEX }\end{array}$ & & \\
\hline BEFORE & AFTER & $\begin{array}{l}\text { P value } \\
\text { (difference) }\end{array}$ \\
\hline 3.92 & 1.42 & \\
\hline 3.52 & 1.52 & 0.001 \\
\hline 2.52 & 1 & \\
\hline 1.52 & 0.9 & \\
\hline 1.92 & 0.85 & \\
\hline 1.51 & 0.9 & \\
\hline 1.91 & 1 & \\
\hline 1.62 & 1.2 & \\
\hline 1.19 & 0.95 & \\
\hline 2.2 & 1.9 & \\
\hline 3.31 & 1.5 & \\
\hline 3.62 & 1.55 & \\
\hline 1.62 & 1.11 & $\succeq$ \\
\hline 1.92 & 1.1 & \\
\hline 1.19 & 0.9 & \\
\hline 1.62 & 0.9 & \\
\hline 1.12 & 0.8 & \\
\hline 1.62 & 0.95 & \\
\hline 1.62 & 0.6 & \\
\hline 1.62 & 0.9 & \\
\hline 1.52 & 0.85 & \\
\hline 1.42 & 0.95 & \\
\hline 1.19 & 0.85 & \\
\hline 2.21 & 0.9 & \\
\hline 2.31 & 0.62 & \\
\hline MEAN (before) & Mean (after) & \\
\hline 1.98 & 1.04 & \\
\hline
\end{tabular}


Table-4- Individual patient data on Probing depth at baseline and follow-up

\begin{tabular}{|c|c|c|}
\hline Probing Depth & & \\
\hline Before & After & P Value \\
\hline 1.51 & 1 & \\
\hline 1.92 & 1.5 & \\
\hline 1.21 & 0.9 & \\
\hline 1.62 & 1 & \\
\hline 2.6 & 1.5 & \\
\hline 2.21 & 1.22 & \\
\hline 3.31 & 1.52 & \\
\hline 2.21 & 1.12 & \\
\hline 3.62 & 1.92 & \\
\hline 4.5 & 2.22 & \\
\hline 1.31 & 0.92 & \\
\hline 1.62 & 0.85 & 0.001 \\
\hline 1.92 & 0.75 & 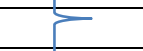 \\
\hline 1.62 & 0.95 & \\
\hline 1.92 & 1 & \\
\hline 1.19 & 1.1 & \\
\hline 1.62 & 0.85 & \\
\hline 1.92 & 1.1 & \\
\hline 2.52 & 1.5 & \\
\hline 3.52 & 1.12 & \\
\hline 1.41 & 1.1 & \\
\hline 1.32 & 1.12 & \\
\hline 1.21 & 0.9 & \\
\hline 1.62 & 1 & \\
\hline 2.21 & 2 & \\
\hline Mean (Before) & Mean (After) & \\
\hline 2.0656 & 1.206 & \\
\hline
\end{tabular}


Assosciation between Emotional intelligence and response to periodontal therapy.

Table-5- Individual patient data on Clinical attachment level at baseline and follw-up

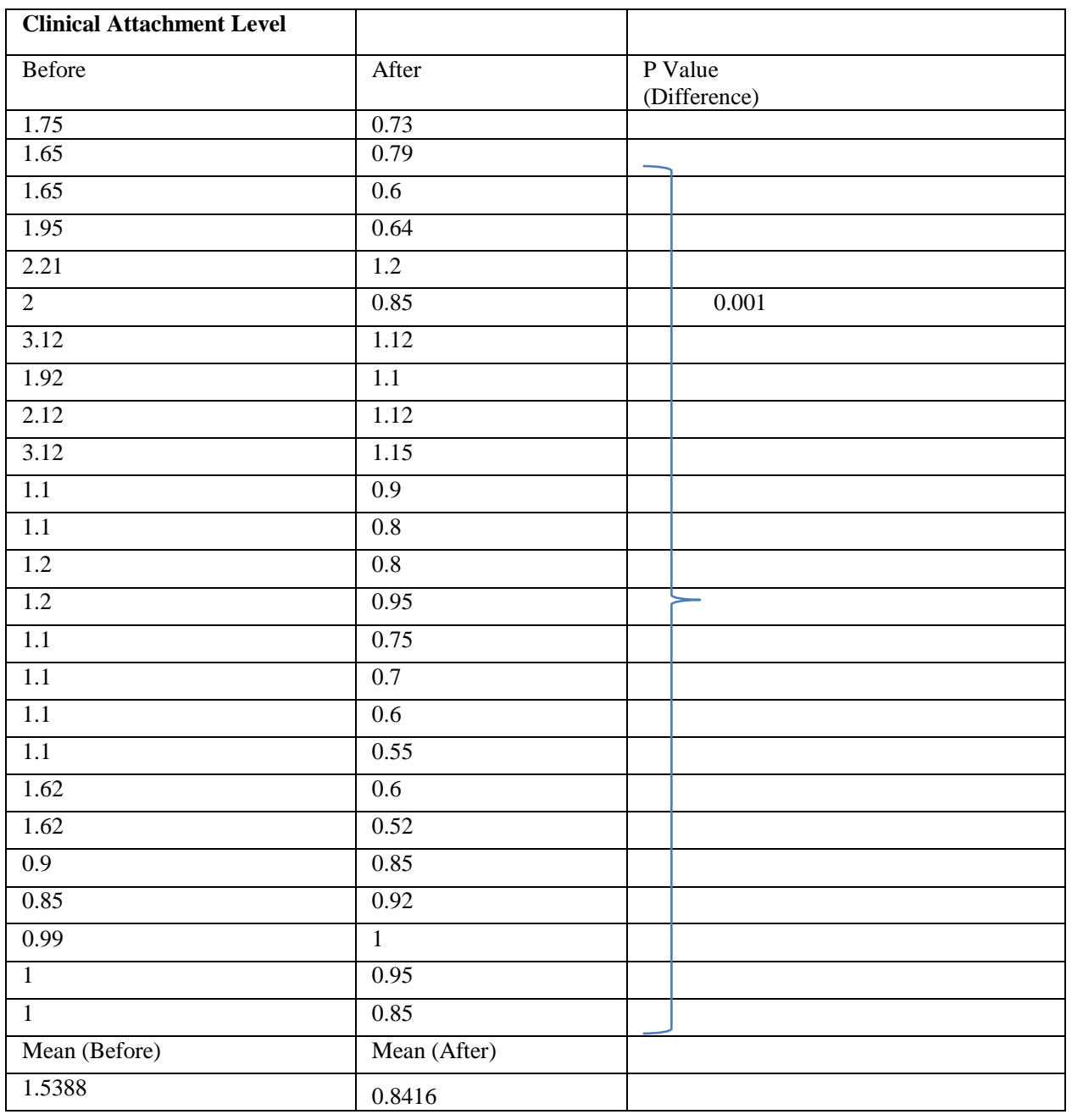

Table-6 - Association between level of education and periodontal parameters .

\begin{tabular}{|c|c|c|c|c|c|c|c|}
\hline \multicolumn{6}{|c|}{ Group Statistics } & \multirow[t]{2}{*}{ T Value } & \multirow[t]{2}{*}{ P Value } \\
\hline & Level Of Education & $\mathrm{N}$ & $\begin{array}{l}\text { Diff. } \\
\text { Mean }\end{array}$ & Std. Deviation & $\begin{array}{l}\text { Std. Error } \\
\text { Mean }\end{array}$ & & \\
\hline \multirow{2}{*}{ PD } & High & 13 & 1.00 & .577 & .160 & \multirow[t]{2}{*}{0.979} & \multirow[t]{2}{*}{0.338} \\
\hline & Low & 11 & .73 & .786 & .237 & & \\
\hline \multirow{2}{*}{ CAL } & High & 13 & .62 & .506 & .140 & \multirow[t]{2}{*}{0.421} & \multirow[t]{2}{*}{0.676} \\
\hline & Low & 11 & .73 & .786 & .237 & & \\
\hline \multirow{2}{*}{ PBI } & High & 13 & .62 & .650 & .180 & \multirow[t]{2}{*}{0.382} & \multirow[t]{2}{*}{0.706} \\
\hline & Low & 11 & .73 & .786 & .237 & & \\
\hline \multirow{2}{*}{ PI } & High & 13 & .92 & .641 & .178 & \multirow[t]{2}{*}{0.047} & \multirow[t]{2}{*}{0.963} \\
\hline & Low & 11 & .91 & .831 & .251 & & \\
\hline
\end{tabular}


Assosciation between Emotional intelligence and response to periodontal therapy.

Table-7- Association between employment status and periodontal parameters

\begin{tabular}{|c|c|c|c|c|c|c|c|}
\hline \multicolumn{6}{|c|}{ Group Statistics } & \multirow[t]{2}{*}{ T Value } & \multirow[t]{2}{*}{ P Value } \\
\hline & Employment Status & \begin{tabular}{l|l}
$\mathrm{N}$ &
\end{tabular} & Mean & Std. Deviation & $\begin{array}{l}\text { Std. Error } \\
\text { Mean }\end{array}$ & & \\
\hline \multirow{2}{*}{ PD } & Yes & 14 & .86 & .663 & 177 & \multirow[t]{2}{*}{0.149} & \multirow[t]{2}{*}{0.883} \\
\hline & No & 10 & .90 & .738 & .233 & & \\
\hline \multirow{2}{*}{ CAL } & Yes & 14 & .64 & .497 & .133 & \multirow[t]{2}{*}{0.212} & \multirow[t]{2}{*}{0.834} \\
\hline & No & 10 & .70 & .823 & .260 & & \\
\hline \multirow{2}{*}{ PBI } & Yes & 14 & .71 & .726 & .194 & \multirow[t]{2}{*}{0.386} & \multirow[t]{2}{*}{0.703} \\
\hline & No & 10 & .60 & .699 & .221 & & \\
\hline \multirow{2}{*}{ PI } & Yes & 14 & .86 & .663 & .177 & \multirow[t]{2}{*}{0.473} & \multirow[t]{2}{*}{0.641} \\
\hline & No & 10 & 1.00 & .816 & .258 & & \\
\hline
\end{tabular}

Table-8- Association between maraital status and periodontal parameters .

\begin{tabular}{|c|c|c|c|c|c|c|c|}
\hline \multicolumn{6}{|c|}{ Group Statistics } & \multirow[t]{2}{*}{ T Value } & \multirow{2}{*}{ P Value } \\
\hline & Marital Status & & Mean & Std. Deviation & Std. Error Mean & & \\
\hline \multirow{2}{*}{ PD } & Yes & 16 & .88 & .719 & .180 & \multirow[t]{2}{*}{0.000} & \multirow[t]{2}{*}{1} \\
\hline & No & 8 & .88 & 641 & .227 & & \\
\hline \multirow{2}{*}{ CAL } & Yes & 16 & .69 & .704 & .176 & \multirow[t]{2}{*}{0.222} & \multirow[t]{2}{*}{0.826} \\
\hline & No & 8 & .63 & .518 & .183 & & \\
\hline \multirow{2}{*}{ PBI } & Yes & 16 & .75 & .775 & .194 & \multirow[t]{2}{*}{0.816} & \multirow[t]{2}{*}{0.423} \\
\hline & No & 8 & .50 & .535 & .189 & & \\
\hline \multirow{2}{*}{ PI } & Yes & 16 & .88 & .719 & .180 & \multirow[t]{2}{*}{-0.385} & \multirow[t]{2}{*}{0.697} \\
\hline & No & 8 & 1.00 & .756 & .267 & & \\
\hline
\end{tabular}

Table-9 - Association between smoking and periodontal parameters .

\begin{tabular}{|c|c|c|c|c|c|c|c|}
\hline \multicolumn{6}{|c|}{ Group Statistics } & \multirow[t]{2}{*}{ T Value } & \multirow[t]{2}{*}{ P Value } \\
\hline & Smoking & $\mathrm{N}$ & Mean & Std. Deviation & Std. Error Mean & & \\
\hline \multirow{2}{*}{ PD } & Yes & 11 & 1.00 & .775 & .234 & \multirow[t]{2}{*}{0.823} & \multirow[t]{2}{*}{0.419} \\
\hline & No & 13 & .77 & .599 & .166 & & \\
\hline \multirow{2}{*}{ CAL } & Yes & 11 & .73 & .786 & .237 & \multirow[t]{2}{*}{0.421} & \multirow[t]{2}{*}{0.678} \\
\hline & No & 13 & .62 & .506 & .140 & & \\
\hline \multirow{2}{*}{ PBI } & Yes & 11 & .73 & .647 & .195 & \multirow[t]{2}{*}{0.382} & \multirow[t]{2}{*}{0.706} \\
\hline & No & 13 & .62 & .768 & .213 & & \\
\hline \multirow{2}{*}{ PI } & Yes & 11 & 1.00 & .775 & .234 & \multirow[t]{2}{*}{0.515} & \multirow[t]{2}{*}{0.612} \\
\hline & No & 13 & .85 & .689 & .191 & & \\
\hline
\end{tabular}

Table-10 - Association between gender and periodontal parameters .

\begin{tabular}{|c|c|c|c|c|c|c|c|}
\hline \multicolumn{6}{|c|}{ Group Statistics } & \multirow[t]{2}{*}{ T VALUE } & \multirow[t]{2}{*}{ P VALUE } \\
\hline & GENDER & $\mathrm{N}$ & Mean & Std. Deviation & Std. Error Mean & & \\
\hline \multirow{2}{*}{ PD } & M & 15 & 1.00 & .756 & .195 & \multirow[t]{2}{*}{1.17} & \multirow[t]{2}{*}{0.333} \\
\hline & $\mathrm{F}$ & 9 & .67 & .500 & .167 & & \\
\hline \multirow{2}{*}{ CAL } & $\mathrm{M}$ & 15 & .73 & .704 & .182 & \multirow[t]{2}{*}{0.654} & \multirow[t]{2}{*}{0.52} \\
\hline & $F$ & 9 & .56 & .527 & .176 & & \\
\hline \multirow{2}{*}{ PBI } & $M$ & 15 & .60 & .632 & .163 & \multirow[t]{2}{*}{0.592} & \multirow[t]{2}{*}{0.56} \\
\hline & $\mathrm{F}$ & 9 & .78 & .833 & .278 & & \\
\hline \multirow{2}{*}{ PI } & $\mathrm{M}$ & 15 & .87 & .743 & .192 & \multirow[t]{2}{*}{0.433} & \multirow[t]{2}{*}{0.669} \\
\hline & $\mathrm{F}$ & 9 & 1.00 & .707 & .236 & & \\
\hline
\end{tabular}


In total, 25 patients were invited to participate in this pilot study. In total, 14 males (56\%) and 11 females (44\%) completed the study. The frequency distribution of demographic and behavioural variables is presented in Table 1. The difference in the levels of plaque and bleeding between the baseline and the follow-up assessment was statistically significant demonstrating a significant reduction in both plaque $(\mathrm{p}<0.001)$ and bleeding levels $(p<0.001)$.In order to test for the presence of confounding variables, the association between changes in plaque and changes in bleeding and different socio-demographic characteristics (gender, employment status, being a part-time or full-time employee and marital status) was tested .A statistically insignificant association was found between gender and bleeding reduction, plaque index between visits . There was no significant association between smoking and changes in plaque or bleeding. In addition, there was no significant association between different domains of level of education, employment status ,maraital status, gender and periodontal parameters. Thus, none of the socio-economic and behavioural factors such as tobacco smoking were found to be related to treatment outcome measures in terms of plaque index, bleeding index , probing depth and clinical attachment loss. The findings of this pilot study are relevant because it raises the possibility of developing an intervention aimed at improving patient's EI, which in turn may improve response to initial treatment of periodontal diseases.

\section{Discussion}

In our present pilot study, in order to test for the presence of confounding variables, the association between changes in plaque and changes in bleeding and different socio-demographic characteristics (gender, employment status, being a part-time or full-time employee and marital status) was tested .A statistically insignificant association was found between gender and bleeding reduction, plaque index between visits . There was no significant association between smoking and changes in plaque or bleeding. In addition, there was no significant association between different domains of level of education, employment status ,maraital status, gender and periodontal parameters. Thus, none of the socio-economic and behavioural factors such as tobacco smoking were found to be related to treatment outcome measures in terms of plaque index, bleeding index , probing depth and clinical attachment loss.

A study of 540 Swedish adults 20-70 years of age has revealed that the three variables smoking, greater age, and higher mean plaque levels were potential risk factors for severe periodontitis. (9)

According to Johnson \& Hill 2004, there is a clear evidence that tobacco smoking is related to adverse response to periodontal treatment.(10) In 1991, a radiographic study of alveolar bone loss in Swedish dental hygienists demonstrated that the distance between the cemento-enamel junction and the interdental septum was significantly greater in smokers than in nonsmokers and increased with increasing smoking exposure. There have been other reports of less bleeding in smokers with periodontitis, suggesting that nicotine could mediate its vasoactive effects on a local basis.Smoking (risk factor) and age (risk determinant) are well-known and wellstudied risks of periodontal diseases. $(11,12,13,14)$

Becker et al. (1998) have suggested that patients with a more positive view of themselves were more likely to comply with continued maintenance therapy. (14)

Lower educational attainment, which is a close correlate of IQ, may also directly lead to poorer coping strategies, higher BMI , lower levels of dental services use, low degree of periodontal health awareness, and irregular oral self-care practices, that in themselves are linked to poor oral hygiene habits may lead to higher levels of dental plaque. Studies have demonstrated that socio-demographic factors, such as low income, ethnicity and education play a role in periodontal disease pathogenesis .( 16) A number of epidemiological studies have shown that there are gender differences in appearance as well as the social and psychological impact on oral health (17).Psychosocial and psychological factors may influence the aetiology of periodontal diseases (18).Despite the evidence regarding the relationship between the aetiology ofperiodontal disease and psychosocial and psychological factors, there are few studies that have tested the association between these factors and the outcome of periodontal treatment. Axtelius et al. (1998) have suggested that patients with a more rigid personality and a less stressful psychosocial situation in the past tend to respond better to periodontal treatment(19).

Dumitrescu et al .stated that, emotional intelligence might be a psychosocial risk marker that influences self-reported oral health status and behaviour. (20). Some evidences also suggests an inverse association between socio - economic status and periodontal diseases. $(21,22,23)$

In a study to explore how dental undergraduates with different levels of emotional intelligence (EI) cope with stress. A K H Pau et.al found that High EI students were more likely to adopt reflection and appraisal, social and interpersonal, and organisation and time-management skills. Low EI students were more likely to engage in health-damaging behaviours. (24)

Gamboa ABO et. al investigated the relationship between different domains of EI, and initial response to asimplified non-surgical treatment protocol in 29 patients with chronic periodontitisThere was a significant overall reduction in plaque and bleeding. Plaque reduction was positively associated with the EI construct of 
intentionality, resilience,constructive discontent and personal power (Spearman's rank test). Reduction in bleeding was positively correlated with resilience, constructive discontent and intuition. This pilot study demonstrated an association between EI domains and short-term changes in plaque and bleeding, and suggest that initial responses to standardized periodontal treatment may be partly related to EI. (25)

Thus , in our present study , the socio-economic and behavioural factors such as tobacco smoking were found to be related to treatment outcome measures in terms of plaque index, bleeding index , probing depth and clinical attachment loss. The size of the sample was small and did not allow for multivariate modelling. Further researches are needed in order to test the effect of EI in the response to more advanced therapies.

\section{Conclusion}

We found an association between EI domains and short-term changes in plaque and bleeding, and suggest that initial responses to standardized periodontal treatment may be partly related to EI. Although there is evidence regarding pathogenesis of periodontal disease and assosciated factors,additional research is necessary to isolate personality factors often assosciated with the behavioral mechanism of non-compliance to PMT appointments..There is also need for further research inorder to test the effect of EI domains on the uptake of a positive behaviour such as smoking cessation following the introduction of smoking counselling in periodontal therapy.

\section{References}

[1]. CostaFO,Cota LO, Lages EJ, et. al.Progression of periodontitisin a sample of regular and irregular compliers under maintanence therapy. J Periodontol 2011;82:1279-1287.

[2]. Tonetti MS ,Steffen P.Initial extractions and tooth loss during supplemental care in a periodontal population seeking comprehensive care.JClinPeriodontol 2000;824-831.

[3]. Fardal $\mathrm{O}$,JohannessenAC.Tooth loss during maintanence following periodontal treatment in a periodontal practice in Norway.JClinPeriodontol 2004;31:550-555.

[4]. Costa FO, Cota LOM.Oral impact on daily performance,personality traits and compliance in maintanence periodontal therapy.JPeriodontol 1993;64:311-314.

[5]. Becker, B. E., Karp, C. L., Becker, W. \& Berg, L. (1998) Personality and stressful life events. Differences between treated periodontal patients with and without maintenance.Journal of Clinical Periodontology15, 49-52.

[6]. Mayer JD,Salovey P. What is emotional intelligence?In:SaloveyP,Slutyer D ,eds.Emotional development and emotional intelligence :Implications for educators,Newyork:Basic books ; 1997:3-31

[7]. Extremera, N. \& Fernandez-Berrocal, P. (2002) Relation to perceive emotional intelligenceand health-related quality of life of middleaged women. Psychological Reports 91, 47-59.

[8]. Mangal SK .Manual for Emotional intelligence inventory : National psychological corporation.

[9]. Norderyd O, Hugoson A (1998). Risk of severe periodontal disease in a Swedish adult population.A cross-sectional study.ClinPeriodontol 25:1022-1028.

[10]. Johnson, G.K \& Hill, M.2004.Cigarette smoking and periodontal patient .Journal of Periodontology 75,196-206

[11]. Bergstrom I ,Eliasson S, Preber H (1991). Cigarette smoking and periodontal bone loss. I Periodontol 62:242-246.

[12]. Bergstrom J, Floderus-Myrhed B. Co-twin control study of the relationship between smoking and some periodontal disease factors. Community Dentistry and Dental Oral Epidemiology 1983; 11: 113-116)

[13]. Calsina G, Ramón JM, Echeverría JJ. Effects of smoking on periodontal tissues. J ClinPeriodontol 2002; 29

[14]. Streckfus CF, Parsell DE, Streckfus JE, Pennington W, Johnson RB. Relationship between oral alveolar bone loss and ageing among African-American and Caucasian individuals.Gerontology 1999; 45.

[15]. Becker, B. E., Karp, C. L., Becker, W. \& Berg, L. (1998) Personality and stressful life events. Differences between treated periodontal patients with and without maintenance. Journal of Clinical Periodontology 15, 49-52

[16]. Persson GR, Persson RE, Hollender LG, Kiyak HA. The impact of ethnicity, gender, and marital status on periodontal and systemic health of older subjects in the Trials to Enhance Elders' Teeth and Oral Health . J Periodontol 2004; 75: 817.)

[17]. (McGrath C, Bedi R. Gender variations in the social impact of oral health. J Irish Dent Assoc 2000;46:87-91.

[18]. (Marcenes, W. S. \&Sheiham, A. (1992) The relationship between work stress and oral health status. Social Science \& Medicine 35,1511-1520.)

[19]. (Axtelius, B., So“derfeldt, B., Nilsson, A., Edwardsson, S. \&Attstro“m, R. (1998) Therapy- resistant periodontitis. Psychosocial characteristics. Journal of Clinical Periodontology 25, 482-491.)

[20]. Dumitrescu AL. Investigating the relationship between self-reported oral health status, oral health-related behaviors, type A behavior pattern, perceived stress and emotional intelligence.Rom J Intern Med. 2007;45(1):67-76.

[21]. Albandar JM. Periodontal diseases in North America.Periodontology 2000. 2002;29:31-69.

[22]. Oliver RC, Brown LJ, Loe H. Periodontal diseases in the United States population. J Periodontol. 1998;69: 269-278. [PubMed]

[23]. Oliver RC, Brown LJ, Loe H. Variations in the prevalence and extent of periodontitis. J Am Dent Assoc. 1991;122:43-48. )

[24]. A K H Pau, R Croucher, R Sohanpal, V Muirhead\& K Seymour. Emotional intelligence and stress coping in dental undergraduates - a qualitative study. British Dental Journal 197, 205 - 209 (2004) )

[25]. Gamboa ABO, Hughes FJ, Marcenes W. The relationship between emotional intelligence and initial response to a standardized periodontal treatment: a pilot study. J ClinPeriodontol 2005; 32: 702-707.) 